\title{
Combination of narrow bipolar pulses and attempted leaders in Melaka, Malaysia
}

\author{
Nur Asyiqin Binti Mohd Isa ${ }^{1}$, Zikri Abadi Baharudin ${ }^{2}$, Izdihartun Najihah Binti Ahmad Daud, \\ Hidayat Zainuddin ${ }^{1}$ \\ ${ }^{1}$ Fakulti Kejuruteraan Elektrik, Universiti Teknikal Malaysia Melaka, Hang Tuah Jaya, Malaysia \\ ${ }^{2}$ Fakulti Teknologi Kejuruteraan Elektrik and Elektronik, Universiti Teknikal Malaysia Melaka, Hang Tuah Jaya, Malaysia
}

\begin{tabular}{l} 
Article Info \\
\hline Article history: \\
Received Nov 19, 2021 \\
Revised Feb 1, 2022 \\
Accepted Feb 9, 2022 \\
\hline Keywords: \\
Association \\
Attempted leaders \\
Initial breakdown \\
Narrow bipolar pulses \\
Pulse trains \\
Tropical thunderstorm
\end{tabular}

\begin{abstract}
This paper presents the characteristic of the positive attempted leaders preceded by positive narrow bipolar pulses (NPBPs). Attempted leaders are the preliminary breakdown process with no subsequent event (return stroke). On the other hand, narrow bipolar pulse is the lightning event commonly isolated and produces a strong electromagnetic field (in a short period). Attempted leaders hardly occurred in the tropics, and the preceding of the NBP (the combination) should be considered unique. In this present study, we found four samples in which the arithmetic means of duration of NPBPs pulse was $32.19 \mu \mathrm{s}$, with separation between the positive attempted leader was $1.86 \mathrm{~ms}$ apart. For the positive attempted leader, the arithmetic means of the whole pulse train, individual pulse and interval pulse of positive attempted leaders were $3.47 \mathrm{~ms}, 29.66 \mu \mathrm{s}$ and $486.53 \mu \mathrm{s}$, respectively. The pulse train in this study seems to fade out fast compared to the isolated positive attempted leader pulse train. Next, the NPBP's pulse duration in this study shows well in agreement with the type of isolated NPBPs indicates that the association does not affect its pulse duration characteristic already present in the title.
\end{abstract}

This is an open access article under the $\underline{C C B Y-S A}$ license.

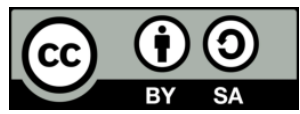

\section{Corresponding Author:}

Zikri Abadi Baharudin

Fakulti Teknologi Kejuruteraan Elektrik \& Elektronik, Universiti Teknikal Malaysia Melaka

Hang Tuah Jaya, 76100 Durian Tunggal, Malaysia

Email: zikri@utem.edu.my

\section{INTRODUCTION}

The preliminary breakdown process is the in-cloud process that triggers the initiation of the first step leader before producing a very high luminous feature of the return stroke. The process has been discussed for several decades by [1]-[7]. Still, the exact mechanism of this process remains not fully understood. Studies show that sufficient charge and concentration of the low positive charge region (LPCR) lead to a higher probability of ground flashes [8]-[10]. However, [11] speculate that a full-fledge of negative cloud-to-ground lightning flashes could be discouraged by the abnormal large in the magnitude of the LPCR. The authors presumed that this condition (dense LPCR relative to main negative charge region) prevented the initial step leader from building into a full-fledge of negative cloud-to-ground flash. As result, there will be no return stroke observed. In this case, it was reported as attempted leaders by [12] and [13] and also as isolated breakdown pulse train by [14]-[16]. This type of initial breakdown is known as an "attempted leader" throughout this study. The previous studies show that attempted leaders scarcely occurred in the lower region compared to the temperate region [14], [15]. Generally, it was due to the less dense LPCR [8], [16]. In most cases, the attempted leader was not preceded by any known even. In other words, they were reported isolated in previous research. 
Narrow bipolar pulses characteristic first report was by [17]. NBPs are the electric fields of intracloud flash that emits strong radio frequency (RF) radiation. This cloud process of a characteristic shape not preceded leader-type of cloud flash and typically bipolar has an initial half cycle followed by an overshoot. The strongest RF radiation emitted appears to be by the cloud processes (NBP), not the ground flashes (return stroke) [14], [17], and [18] report that NBPs are generally not preceded or followed by any other known activities within a time interval of tens millisecond [19]. As compared to the attempted leader, the NBP occurrences are frequent in the tropics. In other words, the emission of NBP pulses increases with the decreasing of latitude [14], [15].

Across the latitudes, in general, there is numerous research on cloud-to-ground lightning flashes compared to cloud flashes. It is most likely due to the harm it caused towards humans at ground level. Consequently, the present information is not adequate in comprehending the physics of cloud flashes. The common reason for this divergence of interest among researchers is the measurement taking constraint associated with the location of the discharge process. Next is due to its less threatening towards human lives and properties at ground level (except who lives at higher altitude) [20]. However, with the advanced, sophisticated, and extensive technologies, there are also damages caused by cloud flashes. Mainly in the aviation industry. Since the NBP emit strong RF radiation in which even surpassed the amplitude of the return stroke, thus, the vulnerability of the avionic system exposed to this electromagnetic field which is also $30 \mathrm{~dB}$ louder than other known lightning discharges processes [21], should not be overlooked.

In this study, we present the cloud flashes of NPBP followed by positive attempted leader analysis of a few parameters within the separation of tens milliseconds apart (after the pulse emission). This study focuses on the association of NPBP with the positive attempted leader's analysis. Specifically, we analyzed the temporal characteristic of these associations and compared them with the isolated results.

\section{METHOD}

The study present 1466 examined data of electric radiation fast field recorded on 19th January-28th April 2017. The measurement conducted in Melaka, Malaysia $\left(2.1896^{\circ} \mathrm{N}, 102.2501^{\circ} \mathrm{E}\right)$ has recorded four samples $(0.27 \%)$ of NPBP pulses with succeeding positive attempted leaders. There are few isolated samples of positive $(\mathrm{N}=28,1.9 \%)$ and negative $(\mathrm{N}=1,0.07 \%)$ attempted leaders observed throughout the measurement campaign. Uniquely, neither negative polarity of NBP nor succeeding attempted leaders recorded in this present study.

The number of positive attempted leader preceded by NPBP activities were found inconsistent with the number of a thunderstorm. Also, they occur at the early and end-stage of the thunderstorm. For instance, on 26th January 2017, only 1 out of 120 samples was found and seen during the early stage. However, on 22nd February 2017, 3 out of 202 data was found and occurred slightly at the early and mid-stage of the thunderstorm. The summary is present in Table 1.

The electric radiation fields of the lightning discharge measurement were using the antenna system consisting of the vertical plate antenna, buffer circuit, coaxial cable, and transient recorder (Teledyne Lecroy HDO4024). The set-up was according to as reported by [22], [23]-[25]. The antenna was set perpendicular to the electric field vector and parallel to the ground for vertical electric field detection. This setting will also keep the horizontal field component away. The physical height of the antenna was 1.5 metres with an effective height of 0.25 metres. A 60-centimetre-long coaxial cable (RG-58) connect the antenna to the electronic buffer circuit. Next, the signal was transmitted from the antenna to a 12-bit digital transient recorder (Teledyne Lecroy HDO4024) using a 10-metre-long coaxial cable (RG-58). This high-speed transient recorder has a $200 \mathrm{MHz}$ High-Definition Oscilloscope. The transmission to the digital transient recorder occurs after passing through the electronic buffer circuit.

The waveform recorded was 2 seconds, while the sampling rate adjusted to $12.5 \mathrm{MS} / \mathrm{s}$. The oscilloscope's trigger setting capture both positive and negative polarities. The trigger level is from $100 \mathrm{mV}$ to $300 \mathrm{mV}$ and the transient recorder operated at 300 milliseconds pre-trigger mode. The rise time of the broadband antenna system (fast field) for the step input pulses was less than 30 nanoseconds, while the decaying time constant was to approximately 15 milliseconds

Table 1. The occurrence of positive attempted leader preceded by positive narrow bipolar pulses with the total activities recorded in Melaka

\begin{tabular}{cccc}
\hline Date & Data & Total of data & Time \\
\hline $26 / 1 / 2017$ & 1 & 120 & $10.03 \mathrm{am}$ \\
$22 / 2 / 2017$ & 17 & 202 & $2.21 \mathrm{am}$ \\
$22 / 2 / 2017$ & 112 & 202 & $6.49 \mathrm{am}$ \\
$22 / 2 / 2017$ & 119 & 202 & $7.42 \mathrm{am}$ \\
\hline
\end{tabular}




\section{RESULTS AND DISCUSSION}

This study focuses on the analysis of positive attempted leaders preceded by NPBPs. Since the negative polarity of both events were not observed, only the positive polarity of the electric radiation field waveform sample is presented (Figure 1). The atmospheric electricity sign convention is applied in this study. The overall positive attempted leader preceded by NPBPs with no activities in between is shown in Figure 1 (a). Next, the extended part of NPBP is in Figure 1 (b), and a whole pulse train of the positive attempted leader is shown in Figure 1 (c).

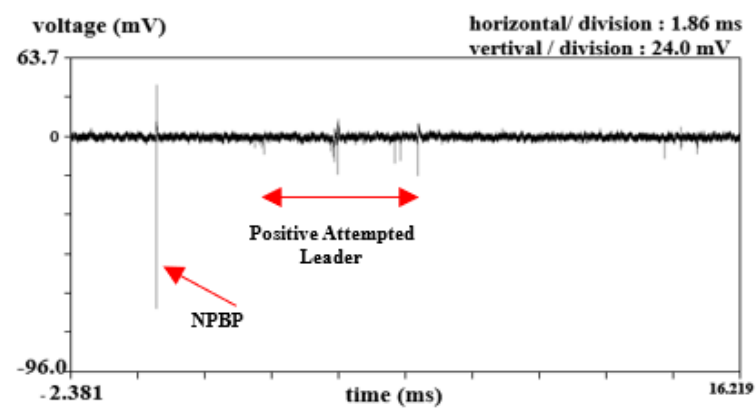

(a)

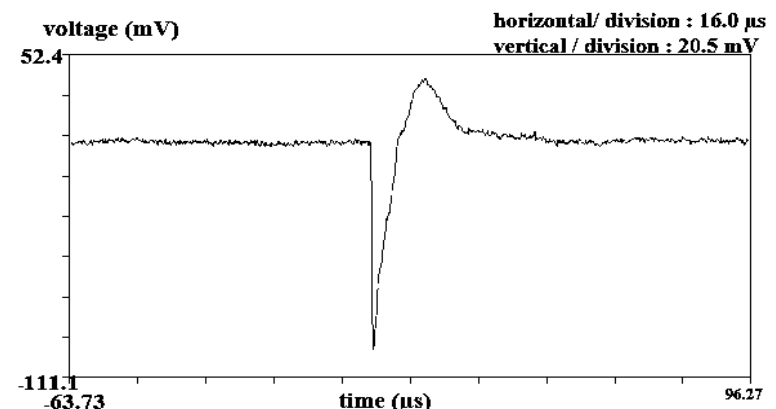

(b)

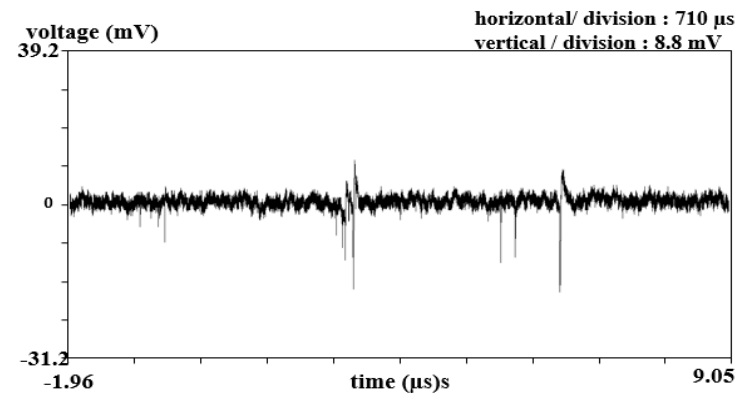

(c)

Figure 1. Electric radiation field waveform of (a) attempted leaders preceded by NPBPs recorded on 22nd February 2017 during Northeast monsoon. No subsequent activity happened. (b) The extended part of positive narrow bipolar pulse and (c) further extended part of the positive attempted leader pulse train

The measurement conducted in Sweden failed to record any NBPs activities, whereas numerous positive NBPs was recorded in Sri Lanka [14]. On the other hand, no attempted leaders were recorded in Sri Lanka. However, often in Sweden with both polarities, but the negative is common [14]. The result indicates that the NBPs are common in tropical thunderstorms while attempted leaders in the higher region. Uniquely, the present study presents the analyzed sample of the combination of NPBPs and the positive attempted leaders. The NPBP was analysed similar to [14][19][15][26]. In this study, two NPBP were recorded with a hump at decaying, one was observed with a peak at the rising while the remaining showed a smooth initial half cycle followed by an overshoot. The duration of NPBPs was $32.19 \mu \mathrm{s}$ with the separation of $1.86 \mathrm{~ms}$ apart before the succeeding event of positive attempted leaders (depicted in Table 2). [19] reported that the NBPs preceded or followed by other lightning activities such as return stroke are commonly separated by a few tens milliseconds of an interval, this duration is parallel with the result in the present study. The NPBPs pulse duration in this study is in good agreement with the isolated type reported by [19] (30.2 $\mu$ s) depicted in Table 3. The comparable results may be due to the same producing thunderstorm since both events happen in the same region. However, the duration of NPBPs in this study is two factors longer than [26] (13.3 $\mu$ s) and two factors shorter than [27] (75 $\mu$ s) in Sri Lanka. Next, the duration of negative NBPs $(24.6 \mu \mathrm{s})$ reported by [19] was slightly shorter than the NPBPs reported in the present study. A summary of NBP activities from different studies is in Table 3.

A few parameters of the positive attempted leader pulse train such as the whole duration pulse train, individual pulse duration and inter-pulse duration as described by [5][22][12][16] and [28] were analyzed. The arithmetic mean of the whole pulse train duration of the positive attempted leader in this study is 3.47 ms. The arithmetic means of the individual pulse train and interval pulse is $29.66 \mu \mathrm{s}$ and $486.63 \mu \mathrm{s}$, respectively (Table 2). The average number of the pulse of the attempted leader is 8.75 . A summary of the temporal analysis is in Table 2. 
Studies of attempted leaders do not associate with known lightning activities is in Table 4. The whole pulse train of positive polarity in this paper $(3.47 \mathrm{~ms}$ ) shows the shortest duration (by two factors) compared to the positive initial polarity of those isolated pulse trains reported by [13] (7.4 ms) and [16] (6.9 $\mathrm{ms})$. As compared to the negative attempted leader, the present study shows a slightly greater result than [12] (2.7 ms), however, four factors greater than [16] (0.98).

According to Proctor [29], the initial leader progression for higher origin discharge (positive discharge) shows 4-5 times slower for either lower origin of cloud or cloud-to-ground flashes. Thus, the positive initial leader progression of the present study is consistent with [29] since its propagation took more time than the negative initial leader progression (from the previous studies). However, the present study has the shortest duration of initial leader progression compared to the positive polarity of those isolated either in the same region or temperate region. The duration pulse train of the present study seemingly faded out faster than the isolated event of positive attempted leaders from the same and higher region. We speculate that the association of NPBPs might be one of the reasons for this behaviour.

Table 2. Temporal analysis of positive narrow bipolar pulses preceding positive attempted leaders

\begin{tabular}{cccccccc}
\hline Reseacher & Location & $\begin{array}{c}\text { NPBP } \\
\text { Pulse duration } \\
(\mu \mathrm{s})\end{array}$ & $\begin{array}{c}\text { Event separation } \\
(\mathrm{ms})\end{array}$ & $\begin{array}{c}\text { Whole } \\
\text { pulse } \\
\text { duration } \\
(\mathrm{ms})\end{array}$ & $\begin{array}{c}\text { Positive attempted leader } \\
\text { Indidual } \\
\text { pulse } \\
\text { duration } \\
(\mu \mathrm{s})\end{array}$ & $\begin{array}{c}\text { Pulse interva } \\
\text { duration } \\
(\mu \mathrm{s})\end{array}$ & $\begin{array}{c}\text { No of pulse } \\
(\mathrm{N})\end{array}$ \\
\hline $\begin{array}{c}\text { Present Study } \\
(2021)\end{array}$ & $\begin{array}{c}\text { Melaka, Malaysia } \\
\left(2.1896^{\circ} \mathrm{N}, 102.2501^{\circ} \mathrm{E}\right) .\end{array}$ & 32.19 & 1.86 & 3.47 & 29.66 & 486.53 & 8.75 \\
\hline
\end{tabular}

Table 3. Comparison of narrow bipolar pulses with earlier studies

\begin{tabular}{|c|c|c|}
\hline \multicolumn{3}{|c|}{ Positive Narrow Bipolar Pulse with succeeding positive attempted leader } \\
\hline Researcher & Location & Pulse Duration $(\mu \mathrm{s})$ \\
\hline Present Study (2021) & $\begin{array}{c}\text { Melaka, Malaysia } \\
\left(2.1896^{\circ} \mathrm{N}, 102.2501^{\circ} \mathrm{E}\right) . \\
\text { Positive Narrow Bipolar Pulse }\end{array}$ & 32.19 \\
\hline [19] & $\begin{array}{c}\text { Johor, Malaysia } \\
(11 \mathrm{~N}, 1031 \mathrm{E}\end{array}$ & 30.2 \\
\hline [26] & $\begin{array}{c}\text { Sri Lanka } \\
(6.91 \mathrm{~N}, 79.61 \mathrm{E})\end{array}$ & 13.3 \\
\hline [27] & $\begin{array}{c}\text { Sri Lanka } \\
\text { Negative Narrow Bipolar pulse }\end{array}$ & 75.0 \\
\hline [19] & $\begin{array}{c}(11 \mathrm{~N}, 1031 \mathrm{E}) \\
\text { Johor, Malaysia }\end{array}$ & 24.6 \\
\hline
\end{tabular}

Table 4. Comparison of attempted leaders with earlier studies

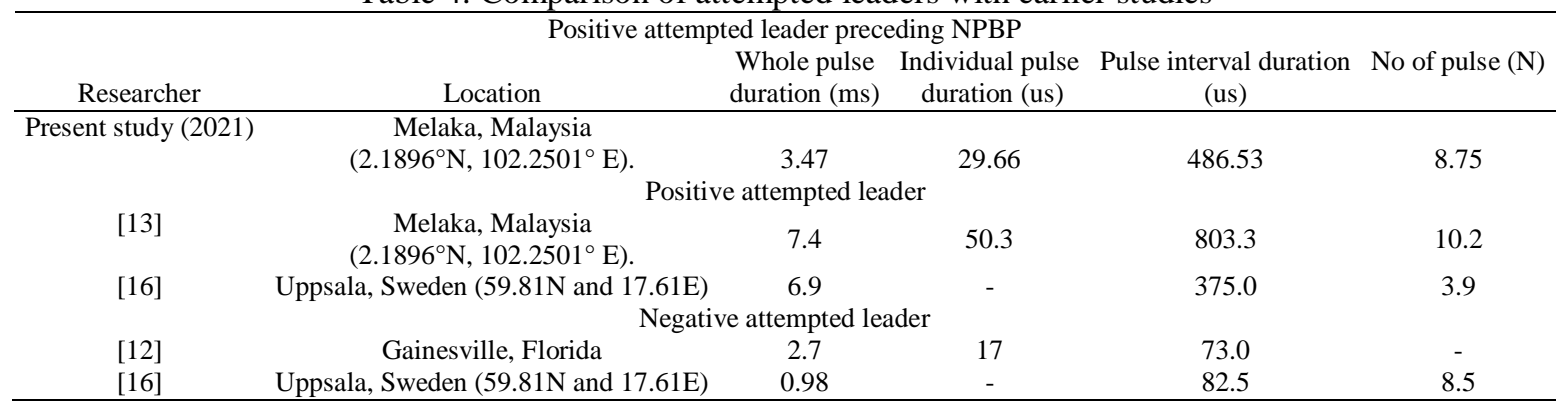

Despite both measurements being in the same region and during the same monsoon seasons, the individual pulse duration in the present study $(29.66 \mu \mathrm{s})$ and [13] $(50.3 \mu \mathrm{s})$ is inconsistent by two factors (Table 4). The present study also shows inconsistency with the individual pulse duration of negative polarity in the higher region (Florida) reported by [12] $(17.0 \mu \mathrm{s})$. On the other hand, for the interval duration, the present result $(486.53 \mu \mathrm{s})$ is less by two factors compared to the isolated of positive polarity reported by [13] (803.3 ms). However, it is slightly similar to [16] (375.0 ms) reported in the temperate region. The present result shows a distinguishable result with negative polarity reported by both [12] and [16]. The smaller duration of the pulse train, individual pulse, and interval pulse of the positive attempted leader in the present study indicates that the association with NBPs lead the pulse train to be faded out fast, narrower pulses and more compact compared to the isolated type (same polarity). 


\section{CONCLUSION}

From 1466 data of electric radiation fast field, only $4(0.27 \%)$ samples of the uncommon event of the attempted leader preceded by NBPs. The arithmetic means of the whole pulse train duration, individual duration, interpulse duration and the number of pulses in the present study is $3.47 \mathrm{~ms}, 29.66 \mu \mathrm{s}, 486.63 \mu \mathrm{s}$ and 8.75 , respectively. The whole pulse train duration is shorter in two factors compared to the result from Sweden and Malaysia. Next, the individual pulse and inter-pulse of positive attempted leader in this study are also shorter in duration than the result from the same region.

The initial leader progression of positive attempted leaders preceded by NPBPs in this study are seen to fade out faster than the isolated breakdown of positive attempted leaders from the same and different region. On the other hand, the NPBPs in this study $(32.19 \mu \mathrm{s})$ shows well in agreement with the isolated NPBPs from the same thunderstorm. This result indicates that the association of NPBPs with the attempted leaders does not affect its pulse duration.

The measurement was during the Northeast monsoon in a tropical thunderstorm. Uniquely, the event subjected in this study appears in positive initial polarity only. Further investigation involves a larger scale of data is required to see whether the result in this study is consistent during other monsoon seasons. Also, to identify the characteristic of negative polarity in which is considered very rare to occur.

\section{ACKNOWLEDGEMENTS}

This work is funded by Zamalah Scheme under Universiti Teknikal Malaysia Melaka. The authors would like to thank the Minister of Education (MOE), Malaysia and the Center for Research and Management (CRIM) of UTeM for equipment and measurement facilities, moral support, and cooperation during our measurement campaign. The device and equipment of this research from the MOE funding under the Exploration Research Grant Scheme (ERGS/2013/FKE/TK02/UTEM/03/01).

\section{REFERENCES}

[1] N. D. Clarence and D. J. Malan, "Preliminary discharge processes in lightning flashes to ground," Quarterly Journal of the Royal Meteorological Society, vol. 83, no. 356, pp. 161-172, Apr. 1957, doi: 10.1002/qj.49708335603.

[2] C. Gomes, V. Cooray, and C. Jayaratne, "Comparison of preliminary breakdown pulses observed in Sweden and in Sri Lanka," Journal of Atmospheric and Solar-Terrestrial Physics, vol. 60, no. 10, pp. 975-979, Jun. 1998, doi: 10.1016/S13646826(98)00007-8.

[3] T. O. T. O. Ushio, Z. I. Z. . Kawasaki, K. Matsu-ura, D. Wang, K. Matsu-ura, and D. Wang, "Electric fields of initial breakdown in positive ground flash," Journal of Geophysical Research Atmospheres, vol. 103, no. D12, pp. 14135-14139, Jun. 1998, doi: 10.1029/97JD01975.

[4] C. Gomes and V. Cooray, "Radiation field pulses associated with the initiation of positive cloud to ground lightning flashes," Journal of Atmospheric and Solar-Terrestrial Physics, vol. 66, no. 12, pp. 1047-1055, Aug. 2004, doi: 10.1016/j.jastp.2004.03.015.

[5] A. Nag and V. A. Rakov, "Electric field pulse trains occurring prior to the first stroke in negative cloud-to-ground lightning," IEEE Transactions on Electromagnetic Compatibility, vol. 51, no. 1, pp. 147-150, Feb. 2009, doi: 10.1109/TEMC.2008.2005488.

[6] Y. J. Y. Zhang, Y. J. Y. Zhang, W. T. Lu, and D. Zheng, "Analysis and comparison of initial breakdown pulses for positive cloud-to-ground flashes observed in Beijing and Guangzhou," Atmospheric Research, vol. 129-130, pp. 34-41, Jul. 2013, doi: 10.1016/j.atmosres.2013.03.006.

[7] T. Wu et al., "Preliminary breakdown pulses of cloud-to-ground lightning in winter thunderstorms in Japan," Journal of Atmospheric and Solar-Terrestrial Physics, vol. 102, pp. 91-98, Sep. 2013, doi: 10.1016/j.jastp.2013.05.014.

[8] V. Cooray and R. Jayaratne, "What directs a lightning flash towards ground?," Sri Lankan Journal of Physics, vol. 1, no. 0, p. 1, Dec. 2000, doi: 10.4038/sljp.v1i0.165.

[9] X. Qie, Y. Yu, and D. Wang, "Characteristics of Cloud-to-Ground Lightning in Chinese Inland Plateau," Journal of the Meteorological Society of Japan., vol. 80, no. 4, pp. 745-754, 2002.

[10] X. Qie, T. Zhang, G. Zhang, T. Zhang, and X. Kong, "Electrical characteristics of thunderstorms in different plateau regions of China," Atmospheric Research, vol. 91, no. 2-4, pp. 244-249, Feb. 2009, doi: 10.1016/j.atmosres.2008.04.014.

[11] A. Nag and V. A. Rakov, "Some inferences on the role of lower positive charge region in facilitating different types of lightning," Geophysical Research Letters, vol. 36, no. 5, Mar. 2009, doi: 10.1029/2008GL036783.

[12] A. Nag and V. A. Rakov, "Pulse trains that are characteristic of preliminary breakdown in cloud-to-ground lightning but are not followed by return stroke pulses," Journal of Geophysical Research Atmospheres, vol. 113, no. 1, Jan. 2008, doi: 10.1029/2007JD008489.

[13] N. A. Isa, Z. A. Baharudin, A. R. M. Ismail, Z. Zakaria, A. I. A. Rahman, and A. A. Zulkefle, "On the existence of attempted leader in tropical thunderstorm," International Journal of Emerging Trends in Engineering Research, vol. 8, no. 11.1 Special Issue, pp. 153-157, Sep. 2020, doi: 10.30534/ijeter/2020/2481.12020.

[14] S. R. Sharma, V. Cooray, and M. Fernando, "Unique lightning activities pertinent to tropical and temperate thunderstorms," Journal of Atmospheric and Solar-Terrestrial Physics, vol. 73, no. 4, pp. 483-487, Mar. 2011, doi: 10.1016/j.jastp.2010.11.006.

[15] M. R. Ahmad, M. R. M. Esa, V. Cooray, Z. A. Baharudin, and P. Hettiarachchi, "Latitude dependence of narrow bipolar pulse emissions," Journal of Atmospheric and Solar-Terrestrial Physics, vol. 128, pp. 40-45, Jun. 2015, doi: 10.1016/j.jastp.2015.03.005.

[16] S. R. Sharma, V. Cooray, and M. Fernando, "Isolated breakdown activity in Swedish lightning," Journal of Atmospheric and Solar-Terrestrial Physics, vol. 70, no. 8-9, pp. 1213-1221, Jun. 2008, doi: 10.1016/j.jastp.2008.03.003.

[17] D. M. Le Vine, "Source of the Strongest RF Radiation From Lightning," Journal of Geophysical Research: Oceans, vol. 85, no. 80, pp. 4091-4095, 1980. 
[18] D. A. A. Smith et al., "A distinct class of isolated intracloud lightning discharges and their associated radio emissions," Journal of Geophysical Research Atmospheres, vol. 104, no. D4, pp. 4189-4212, Feb. 1999, doi: 10.1029/1998JD200045.

[19] N. Azlinda Ahmad, M. Fernando, Z. A. Baharudin, V. Cooray, H. Ahmad, and Z. Abdul Malek, "Characteristics of narrow bipolar pulses observed in Malaysia," Journal of Atmospheric and Solar-Terrestrial Physics, vol. 72, no. 5-6, pp. 534-540, Apr. 2010, doi: 10.1016/j.jastp.2010.02.006.

[20] S. R. Sharma, M. Fernando, and C. Gomes, "Signatures of electric field pulses generated by cloud flashes," Journal of Atmospheric and Solar-Terrestrial Physics, vol. 67, no. 4, pp. 413-422, Mar. 2005, doi: 10.1016/j.jastp.2004.09.007.

[21] W. Rison, R. J. Thomas, P. R. Krehbiel, T. Hamlin, and J. Harlin, “A GPS-based three-dimensional lightning mapping system: Initial observations in central New Mexico," Geophysical Research Letters, vol. 26, no. 23, pp. 3573-3576, Dec. 1999, doi: 10.1029/1999GL010856.

[22] Z. A. Baharudin, N. A. Ahmad, M. Fernando, V. Cooray, and J. S. Mäkelä, "Comparative study on preliminary breakdown pulse trains observed in Johor, Malaysia and Florida, USA," Atmospheric Research, vol. 117, pp. 111-121, Nov. 2012, doi: 10.1016/j.atmosres.2012.01.012

[23] M. F. Galvan, Arturo, "Operative characteristics of parallel-plate antenna to measure vertical electric fields from lightning flashes," 2000, Accessed: Feb. 09, 2022. [Online]. Available: http://urn.kb.se/resolve?urn=urn:nbn:se:uu:diva-40072.

[24] V. Cooray, Ed., The lightning flash. Institution of Engineering and Technology, 2003.

[25] Z. A. Baharudin, N. A. Ahmad, J. S. Mäkelä, M. Fernando, and V. Cooray, "Negative cloud-to-ground lightning flashes in Malaysia," Journal of Atmospheric and Solar-Terrestrial Physics, vol. 108, pp. 61-67, Feb. 2014, doi: 10.1016/j.jastp.2013.12.001.

[26] S. R. Sharma, M. Fernando, and V. Cooray, "Narrow positive bipolar radiation from lightning observed in Sri Lanka," Journal of Atmospheric and Solar-Terrestrial Physics, vol. 70, no. 10, pp. 1251-1260, Jul. 2008, doi: 10.1016/j.jastp.2008.03.002.

[27] V. Cooray and S. Lundquist, "Characteristics of the radiation fields from lightning in Sri Lanka in the tropics.," Journal of Geophysical Research, vol. 90, no. D4, pp. 6099-6109, 1985, doi: 10.1029/JD090iD04p06099.

[28] D. Johari, V. Cooray, M. Rahman, P. Hettiarachchi, and M. M. Ismail, "Characteristics of preliminary breakdown pulses in positive ground flashes during summer thunderstorms in Sweden," Atmosphere, vol. 7, no. 3, p. 39, Mar. 2016, doi: 10.3390/atmos7030039.

[29] D. E. Proctor, "Lightning flashes with high origins," Journal of Geophysical Research Atmospheres, vol. 102, no. 2, pp. 16931706, Jan. 1997, doi: 10.1029/96jd02635.

\section{BIOGRAPHIES OF AUTHORS}
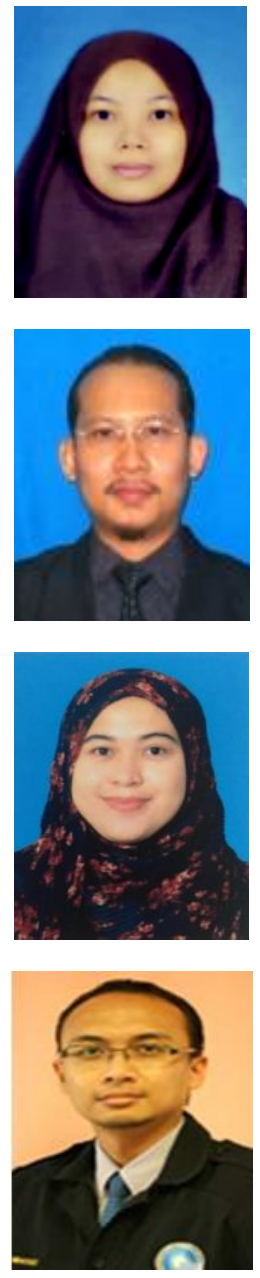

Nur Asyiqin Binti Mohd Isa (D) SI SC P received her bachelor's and master's degrees in applied physics in 2012 and 2014 from the National University of Malaysia (UKM). She teaches Physics for UniKL Foundation Program from 2015 until 2018 before pursuing PhD degree in Electrical Engineering specializing in lightning and protection at Universiti Teknikal Malaysia Melaka. She can be contacted at email: syiqinisa@yahoo.com.

Ts. Dr. Zikri Abadi Baharudin (D) 8d SC P received his PhD degree in Engineering Science with specialization in Atmospheric Discharges in 2014 from Uppsala University, Sweden. He obtained his bachelor's degrees in electrical (Electronics) Engineering and M.Eng. In Electrical (Power) from Universiti Teknologi Malaysia (UTM) in 2001 and 2004, respectively. Currently he is a lecturer at Electrical Technology Industry Department (FTK), Universiti Teknikal Malaysia Melaka. His research interests are lightning and protection, electromagnetic compatibility, and high voltage. He can be contacted at email: zikri@utem.edu.my.

Izdihartun Najihah Binti Ahmad Daud (D) SC SC P received her bachelor's degrees in applied engineering of electrical technology (Industrial Power) in 2017 from the Technical University of Malaysia, Melaka (UTeM). She pursues Master of Science in Electrical Engineering specializing in lightning and protection at Technical University of Malaysia, (UTeM) from 2018 until currently. She can be contacted at email: izdi.najihah94@gmail.com.

PM Dr Hidayat Zainuddin (D) 8 SC P recieved his Ph.D. in Electronic and Electrical Engineering (High Voltage) in University of Southampton, UK. M.Sc. in Electrical Power Engineering with Business, University of Strathclyde, UK and B.Eng. in (Electrical), UTM. His specialization are in condition monitoring of high voltage equipment, testing and failure/degradation analysis of insulation/dielectric materials and finite element analysis modelling. He can be contacted at email: hidayat@utem.edu.my. 